\title{
VR Simulation Sickness from Experience Information Disparity
}

\author{
YangMi Lim ${ }^{1}$ and SangHun $\mathrm{Nam}^{2}$ \\ ${ }^{1}$ School of Digital Media, Duksung Women's University, 33, Samyangro 144-gil, \\ Dobong-gu, Seoul 132-714, Korea \\ ${ }^{2}$ Center of Human-centered Interaction for Coexistence, \\ No. L8325, KIST, Hwarangno 14-gil 5, Seongbuk-gu, Seoul 136-791, Korea \\ 1yosimi@duksung.ac.kr, ${ }^{2}$ sanghunnam@gmail.com
}

\begin{abstract}
With the recent popularization of low-cost virtual reality $(V R)$ devices, VR contents have rapidly increased, but a key issue is that most of the applications that have been developed thus far are causing simulation sickness or cyber sickness. This study is on whether or not the dizziness occurs when there is an overload of elements that give us spatial sense, or when distance information from the real world and the world of virtual reality are mismatched. We performed experiments on changes in movement speed according to FoV, brightness, movement distance, using element tests regarding experience information disparity and describe the results of our experiments. The analysis data from this study are data that are required by general VR developers and users, and will become crucial analysis data. The data are expected to be useful to developers and gamers for future VR content or during the VR game development stage.
\end{abstract}

Keywords: VR, simulation sickness, experience information, VR device, VR contents

\section{Introduction}

With the recent propagation of costly HMD devices that can display stereoscopic images in virtual reality with Google Cardboard, content and game development for VR have rapidly increased. During "CES 2016" in Las Vegas, which is the world's biggest IT appliance and technology exhibition, around 40 global IT corporations showcased various devices that offered a virtual reality experience [1]. Many Chinese corporations attended demonstrated the low-cost VR products, and this showed a significant decrease in general price, which was the biggest obstacle in the purchase of VR products.

With the recent popularization of low-cost virtual reality (VR) devices, VR contents have rapidly increased, but a key issue is that most of the applications that have been developed thus far are causing simulation sickness or cyber sickness. This can be interpreted by saying physiological studies, which regarding the cognitive senses of the human body, is quite lacking in comparison to the rapid development of technology. Therefore, this study focuses on the cognitive senses of the human body. The reason behind the dizziness associated with VR simulation is more often attributable to personal experience and the fact that the information that was experienced by the brain through action does not match, rather than the dizziness that results from sensory conflict from traditional physiological theories through a defect in the cochlea [2]. When we break down the reason for this dizziness, they can be categorized into technological factors (function of VR devices, etc.), experience information disparity elements, and personal elements (height, field of vision, visual abilities, etc.). Of these, the "experience information disparity elements" refers to a phenomenon in which dizziness is experienced because the elements that were felt based on monocular depth cues, which grants us our spatial sense, is different from what our brains perceived thus far. In general, the human body perceives spatial sense by perceiving objects with two eyes, which is also called 
binocular depth cues. There are techniques that express spatial sense from a 2dimensional plane aside from binocular depth cues, which is a physiological theory, including linear perspective, shading, advanced colors and receding colors, texture gradients, overlap phenomenon, etc. [3]. These techniques are reputed as the expressions for spatial sense through monocular depth cues, and painters from the past have used these techniques to express the same spatial sense that is experienced in reality. A realistic expression of spatial sense through monocular depth cues has become an important method when it comes to creating stereoscopic images. In a study that observed this fact, the disparity between techniques that express spatial sense based on monocular depth cues and the information perceived by the brain (experience information disparity phenomenon) was seen as a phenomenon that induces dizziness, and an analysis was performed on this phenomenon.

\section{Related Research}

In one interactive zone at CES 2016, a "Gear VR 4D Interactive Zone" was demonstrated where people could experience 360 degree stereoscopic images through "Gear VR" and 4D chairs. There is the study conducted on the simulation dizziness that occurs when immersed in virtual reality content or games. Among studies on simulation dizziness, there is a correlation study that was conducted by the "Army Research Institute" on the movements of the VR world and the movements of the real world. This study was on the correlation between what users felt during and after experiencing the VR world and the movements in the VR world aside from the user's own movements (selfmotion) [4]. The "Teleoperators and Virtual Environments" journal presented study results that attributed simulation dizziness to the user's loss of directional sense in virtual reality as a result of the self-motion induced by visual stimulation, but that there is a motor disturbance in the eyes in the real world [5]. Unreal Engine presented the reasons for simulation dizziness as HMD frame speed, FoV, Walking Box, light and color brightness, changes in movement speed from spatial forms, changes in movement speed from moving distances, motion blur post, user height, location tracking error, background complexity, etc. [6,7]. Oculus Lift VR also determined that simulator sickness is mostly attributable to the conflict between visual and bodily senses, which include acceleration, degree of control, duration of simulator use, altitude, binocular disparity, field-of-view, latency, distortion correction, flicker, experience, and users are forewarned of these elements when using devices [8]. There are more studies overseas because most VR devices, such as the high-cost Oculus Lift (left) and low-cost Google Cardboard (right), are developed by overseas companies, and most VR content is developed using tools such as Unreal SW and Unity 3D SW that are also from overseas [9]. However, the content development has been quickly on the rise in Korea with the availability of low-cost VR devices that can be purchased at just 10 20 dollar so that anyone can play using smartphone apps. There are development techniques in which elements such as light and color brightness, changes in movement speed from spatial forms, changes in movement speed from moving distances, motion blur post, user height, or background complexity must be limited during the process of developing VR content. However, there are no detailed studies that were systematically performed regarding factors that cause dizziness. A study on development methods that minimize dizziness during the process of content development will be valuable so that developers can secure a competitive edge in the overseas VR market. 


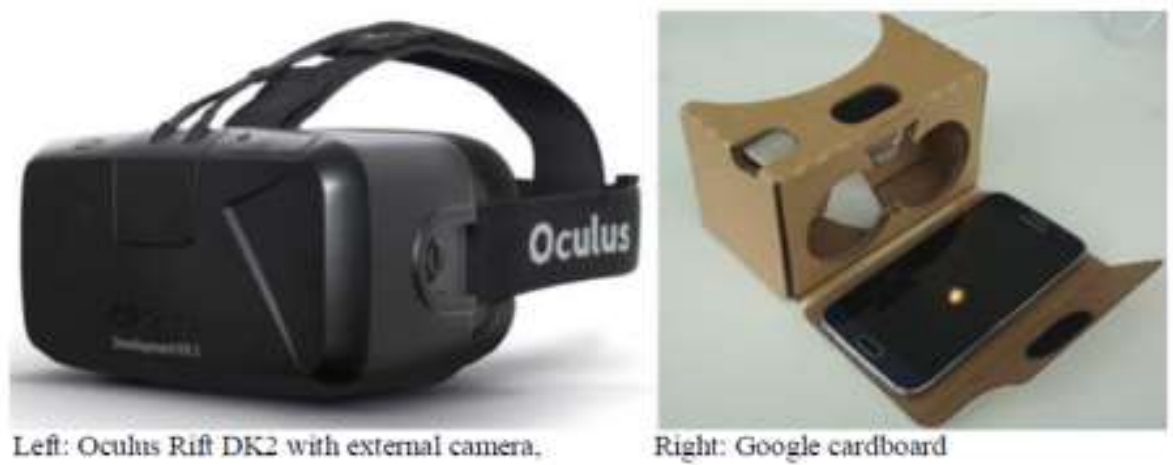

Figure 1. VR HMD Devices

\section{Spatial Sense Expression Techniques based on Monocular Depth Cues and the Experience Information Disparity Phenomenon}

Unlike binocular depth cues, which the human body automatically processes due to having two eyes, monocular depth cues refer to factors that enable one to have spatial sense during the process of learning through acquired experience. These factors may include view angle size according to vision, retinal imaging, linear perspective, penetrative perspective, atmospheric perspective, shading, overlapping, motion, contouring, and shadows [10]. For linear perspective, the objects are placed in stable locations so that the perceived distance of objects in virtual reality is similar to that of the real world. In general, the human body feels stability in visual distances through zero parallax or convergence points, and objects are placed in positive locations in virtual reality or stereoscopic images so that users can experience intense negatives or intense distancing in order to overstimulate their senses. This is so that the human body can sufficiently experience the proper spatial senses. However, excessive negative/positive expressions induce dizziness, because the perspective distance information that the body is used to through experience in the real world is different from that of virtual reality. This experience disparity phenomenon increases dizziness as time passes because the intense phenomenon accumulates. Figure 2 describes the negative and positive parallax based on zero parallax.

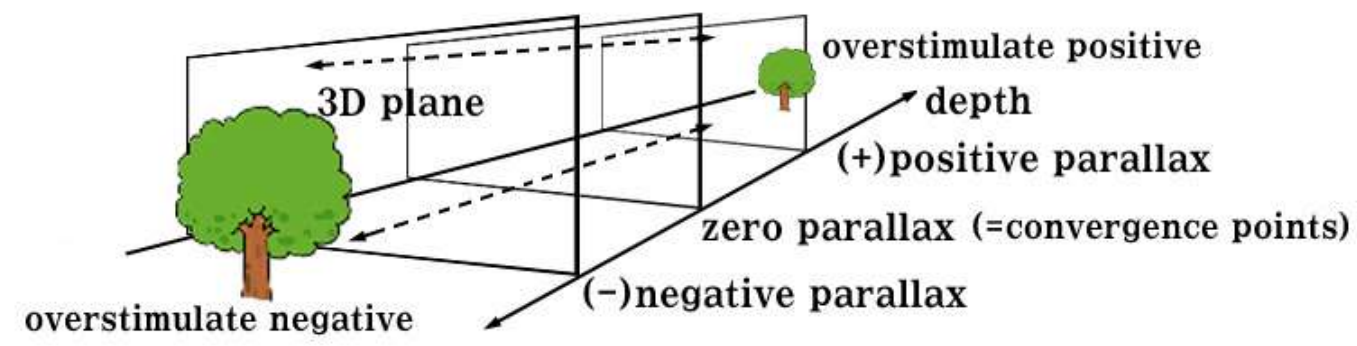

\section{Figure 2. Understanding the Visual Depth of Spatial Imagery According to Time Differences Based on Z-Axis}

The aforementioned techniques that enable one to have spatial senses based on experience are often used in paintings in order to express a sense of space on 2dimensional surfaces. Table 1 is a compilation of spatial sense expression techniques based on experiential factors that are used in paintings after the Renaissance era to exhibit a sense of space. 
Table 1. Analysis of Elements Used to Exhibit Sense of Space in Paintings

\begin{tabular}{|c|c|c|c|c|}
\hline Year & $\begin{array}{l}\text { Perspective } \\
\text { Cause }\end{array}$ & $\begin{array}{l}\text { Perspective } \\
\text { Technique }\end{array}$ & Artist & $\begin{array}{l}\text { Name of } \\
\text { Painting }\end{array}$ \\
\hline 1427 & $\begin{array}{l}\text { Linear } \\
\text { perspective } \\
\text { effect }\end{array}$ & $\begin{array}{l}\text { Linear } \\
\text { perspective } \\
\text { method }\end{array}$ & Masaccio & $\begin{array}{l}\text { The Holy } \\
\text { Trinity }\end{array}$ \\
\hline $1503-6$ & \multirow{4}{*}{$\begin{array}{l}\text { Linear } \\
\text { perspective } \\
+ \text { light effect }\end{array}$} & $\begin{array}{l}\begin{array}{l}\text { Atmospheric } \\
\text { perspective }\end{array} \\
\end{array}$ & $\begin{array}{l}\text { Leonardo } \mathrm{Da} \\
\text { Vinci }\end{array}$ & Mona Lisa \\
\hline 1600 & & Shading & Caravaggio & $\begin{array}{l}\text { The Calling } \\
\text { of St. } \\
\text { Matthew }\end{array}$ \\
\hline 1632 & & Lighting & Rembrandt & $\begin{array}{l}\text { Philosopher } \\
\text { in Meditation }\end{array}$ \\
\hline $1662-5$ & & $\begin{array}{l}\text { Texture } \\
\text { gradient }\end{array}$ & Vermeer & $\begin{array}{l}\text { The Music } \\
\text { Lesson }\end{array}$ \\
\hline 1872 & \multirow{2}{*}{$\begin{array}{l}\text { Linear } \\
\text { perspective }+ \\
\text { color effect }\end{array}$} & $\begin{array}{l}\text { Chromatic } \\
\text { contrast }\end{array}$ & Monet & Sunrise \\
\hline 1888 & & $\begin{array}{l}\text { Advanced } \\
\text { color/Receding } \\
\text { color }\end{array}$ & Gogh & $\begin{array}{l}\text { Café Terrace } \\
\text { at Night }\end{array}$ \\
\hline 1878 & $\begin{array}{l}\text { Eclipsing } \\
\text { effect }\end{array}$ & Overlapping & Gustav & $\begin{array}{l}\text { View of } \\
\text { Rooftops }\end{array}$ \\
\hline 1912 & $\begin{array}{l}\text { Movement } \\
\text { effect }\end{array}$ & $\begin{array}{l}\text { Motion } \\
\text { parallax }\end{array}$ & Giacomo Balla & $\begin{array}{l}\text { Dynamism of } \\
\text { a Dog on a } \\
\text { Leash }\end{array}$ \\
\hline
\end{tabular}

Table 2. Correlation between Motion Sickness Elements from VR Simulation and Spatial Techniques Used in 2-Dimensional Surfaces

\begin{tabular}{|l|l|l|}
\hline Sickness Factor & Description & $\begin{array}{l}\text { Perspective } \\
\text { Technique }\end{array}$ \\
\hline $\begin{array}{l}\text { HMD Frame } \\
\text { Speed }\end{array}$ & $\begin{array}{l}\text { The speed of HMD devices become a } \\
\text { motion sickness factor at slower frames. }\end{array}$ & $\begin{array}{l}\text { Motion } \\
\text { parallax }\end{array}$ \\
\hline FoV & $\begin{array}{l}\text { The physical geometry of the head set and } \\
\text { lenses must be identical based on a person's } \\
\text { field of view. Supported as a fixed value in } \\
\text { SDK. }\end{array}$ & $\begin{array}{l}\text { Linear } \\
\text { perspective } \\
\text { method }\end{array}$ \\
\hline $\begin{array}{l}\text { Movements that } \\
\text { are linked to } \\
\text { Walking } \\
\text { Bob/events }\end{array}$ & $\begin{array}{l}\text { Movements that are linked to bomb } \\
\text { explosions or effects that shake the camera } \\
\text { according to walking distance. Motion } \\
\text { Sickness Factor }\end{array}$ & \\
\hline $\begin{array}{l}\text { Light and color } \\
\text { brightness }\end{array}$ & $\begin{array}{l}\text { Flashy lighting is a motion sickness factor. } \\
\text { Darken colors more than usual. Better to } \\
\text { use darker lighting with cool colors. }\end{array}$ & $\begin{array}{l}\text { Lighting and } \\
\text { shading }\end{array}$ \\
\hline $\begin{array}{l}\text { Sense of } \\
\text { direction } \\
\text { according to } \\
\text { spatial } \\
\text { movements }\end{array}$ & $\begin{array}{l}\text { Sense of direction is lost when climbing } \\
\text { stairs or during a maze, rendering motion } \\
\text { sickness. }\end{array}$ & \\
\hline $\begin{array}{l}\text { Changes in } \\
\text { movement speed } \\
\text { from moving }\end{array}$ & $\begin{array}{l}\text { Players must start at max speed and play } \\
\text { slowly. Slowly accelerating to max speed } \\
\text { becomes a motion sickness factor. }\end{array}$ & $\begin{array}{l}\text { Motion } \\
\text { parallax }\end{array}$ \\
\hline
\end{tabular}




\begin{tabular}{|l|l|l|}
\hline distances & Movement speed uses fixed ratios. & \\
\hline User height & $\begin{array}{l}\text { The height of the character using the VR } \\
\text { headset must be similar to the actual height } \\
\text { of the user. }\end{array}$ & \\
\hline
\end{tabular}

Table 2 was compiled with Unreal Engine with regard to dizziness. When these dizziness factors were compared to techniques that exhibit a sense of space based on monocular depth cues, they were shown to have positive correlation. The items that were able to be tested in this study can be broken down into 3 types: FoV, brightness of light, and changes in movement speed according to moving distances. Because HMD frame speed differs for each manufacturer, Unreal Engine and Unity3D support the frame speed shown in Table 3, thus making it unfit to test in this study.

Table 3. Frame speed that are supported by Unreal Engine for each HMD device

\begin{tabular}{|l|l|}
\hline HMD Device & Target Frame Speed \\
\hline DK1 & 60 FPS \\
\hline DK2 & 75 FPS \\
\hline Rift Retail & 90 FPS \\
\hline Vive & 90 FPS \\
\hline Gear VR & 60 FPS \\
\hline
\end{tabular}

Field of view (FOV: Visual range that can see the information at a glance) is limited to $200^{\circ}$ horizontally and $130^{\circ}$ vertically, so that a person focuses on the information at the visual center while searching for information. Field of view has limitations during testing because it is fixed in HMD, but it can be tested in this study because it is related to the user's height.

Light and color brightness can exhibit a sense of space through lighting and shading. However, because dizziness may be caused by the intensity of light, we also tested this element.

With regard to changes in movement speed from moving distances, Unreal claimed that dizziness from moving distances was due to changes in speed. However, the dizziness is not caused by a mere change in speed, but can be attributed to the speed changes in the VR space's background and objects that is caused with changes in speed. Figure 3 shows the phenomenon in which trees near the bus move faster according to the bus's movements, while faraway mountains move slowly. Therefore, a person experiences perspective by comparing speed (motion parallax) [11]. The bus, tree, and mountain's change in speed must be designed to mimic the changes in the real world so that the experience information disparity phenomenon does not arise. Elements that can be tested are shown in Table 4.

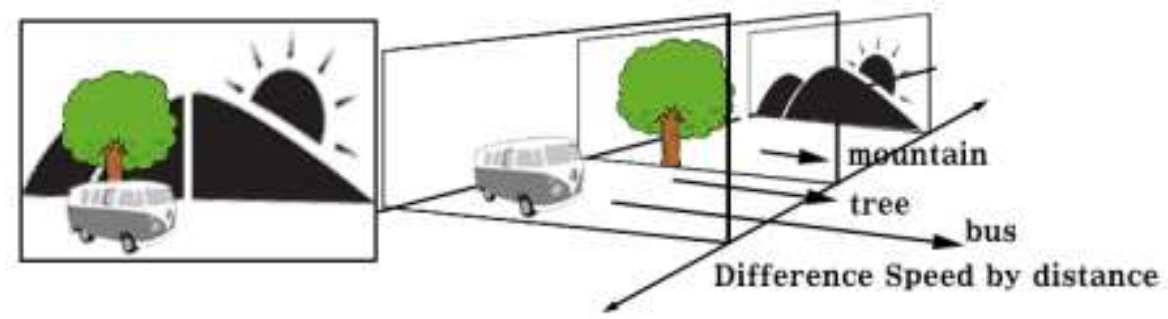

Figure 3. Movements of Nearby and Faraway Objects 


\section{Table 4. Correlation between Motion Sickness Elements from VR Simulation and Spatial Techniques Used in 2-Dimensional Surfaces}

\begin{tabular}{|l|l|l|}
\hline Sickness Factor & Perspective Technique & Able to test \\
\hline HMD Frame Speed & Motion parallax & Fixed \\
\hline FoV & $\begin{array}{l}\text { Linear perspective method, simulated } \\
\text { with regard to user height }\end{array}$ & Possible \\
\hline $\begin{array}{l}\text { Light and color } \\
\text { brightness }\end{array}$ & Lighting and shading & Possible \\
\hline $\begin{array}{l}\text { Changes in movement } \\
\text { speed according to } \\
\text { moving distances }\end{array}$ & Motion parallax & Possible \\
\hline
\end{tabular}

\section{Simulation Design of Spatial Sense Element for Testing}

This section describes the simulation design and production process, focusing on the sickness factors in Table 4. Unity3D was used to produce an application, and the smartphone display was used to show a video. First, we used the Google Cardboard device and the Gear VR Device with the Samsung Galaxy Note 7 for VR videos. The Gear VR that came as a set with the Galaxy Note 7 supports a $101^{\circ}$ field of view as a fixed value [12]. Cardboard V2 supports a range of $90^{\circ}$ according to the smartphone's display size [13].

\subsection{Height Simulation of FoV-related User}

FoV is supported as a fixed value in VR devices and software. However, because a range of vision typically changes according to user height, it is a condition that must be considered when developing VR content. In a simulation created by Unity3D, there is a difference in the range of vision when users are sitting and when they are standing.

The visual world changes according to the user's eye level in the real world, thus this element must be modifiable. In other words, there is a difference in what the user sees in virtual reality when they are sitting and standing with regard to VR camera settings. When the user is sitting, the starting point of the camera must be set closer to the ground. When they are standing, it must be set far from the ground.

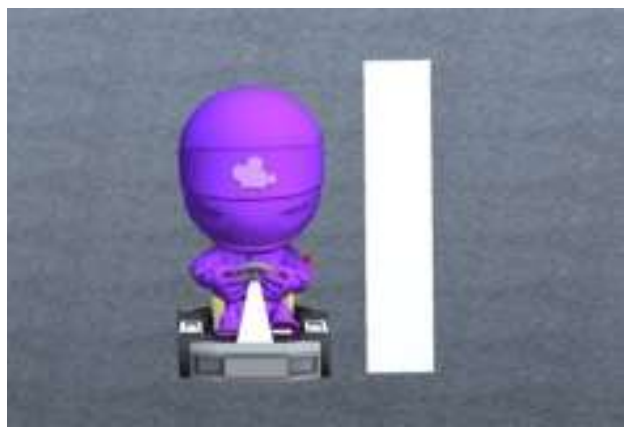

\section{Figure 4. Standard Units for User Height Settings Based on a 1m Character}

Figure 4 shows the process of setting units in order to enter the user's height value in Unity3D. To accurately measure the value of 1 unit that is used in Unity3D, the height of a character created in 3DMax and the height of a $1 \mathrm{~m}$ ruler is compared to create a character that can be used as the standard as shown in Figure 4. This character with a $1 \mathrm{~m}$ height becomes the standard unit for setting the height of the game according to the user's height. Figure 5 is an environment setting screen where the simulation user selects their height. It provides a range of $100-199 \mathrm{~cm}$, which can include heights when an average 
adult is sitting or standing. Users can configure this setting by moving and clicking the location of the red circle. Users must move their head and click when using Cardboard. For Gear VR, there is a button on the right so that users can click without having to move their head.

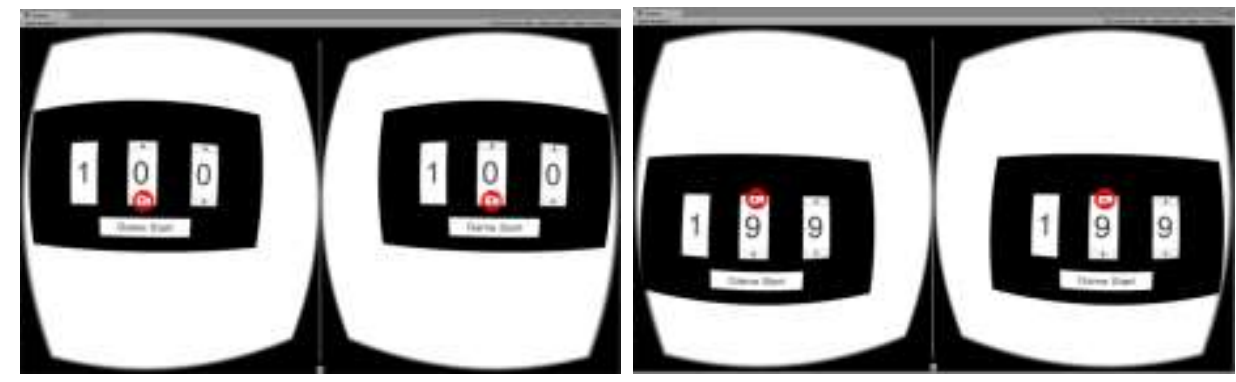

Figure 5. Height Selection Screen

Figure 5 shows the FoV screen according to the height that was entered when the game began. Figure 6(the left side) shows the field of view when height is set to the minimum value of $100 \mathrm{~cm}$ (selection based on when user is sitting). The right side shows the field of view when height is set to the maximum value of $199 \mathrm{~cm}$ (selection based on when user is standing). Field of vision differs according to the value entered so that each user is given images that are optimized for them.
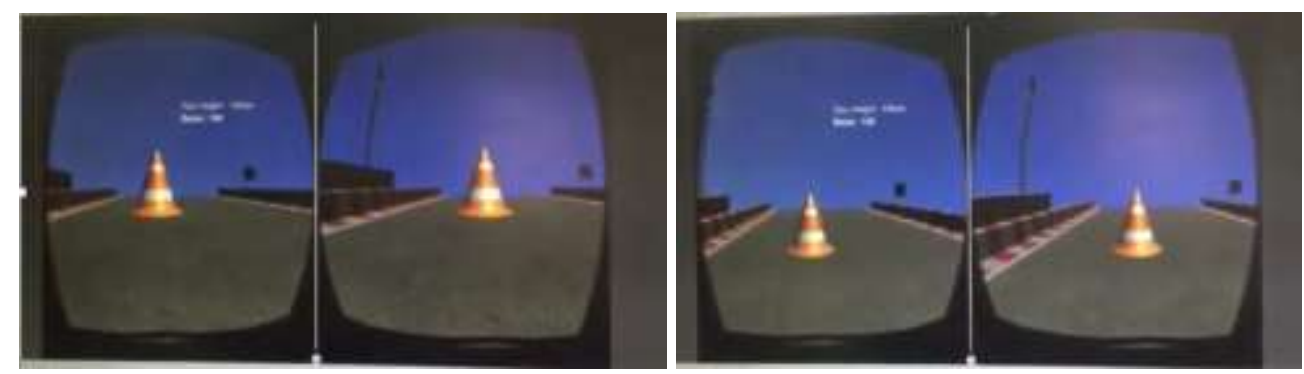

Figure 6. Left: $100 \mathrm{~cm}$, Right: $199 \mathrm{~cm}$

In other words, Figure 6 shows the range of vision with an artificially adjusted camera zero parallax according to the user's sitting and standing height. To create an environment that is similar to the range of vision in the real world, the camera component location was made to match the character's eye level in Unity3D. The reason why this is necessary is because the location of other objects and backgrounds must also be placed to match the real world. The distance that is visible from an actual distance and the proportion of building sizes had to be calculated in order to place them in a way that matches the real world. Distance was set to match the changing size of a street lamp that is $1 \mathrm{~m}$ away from the character. The height of the street lamp was in accordance with the standard height of $4 \mathrm{~m}$ that is required when installing actual street lamps. Figure 7 shows how height was set using a $4 \mathrm{~m}$ rule that was created in 3DMax to set up realistic street lamps. 


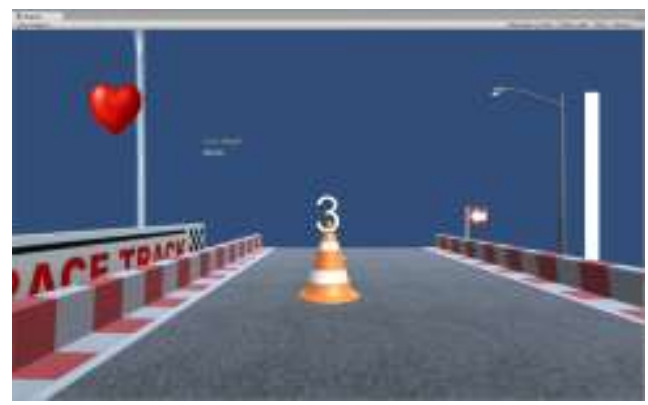

Figure 7. Location of Street Lamps Used in an Actual Simulation by Using A $4 \mathrm{~m}$ Ruler

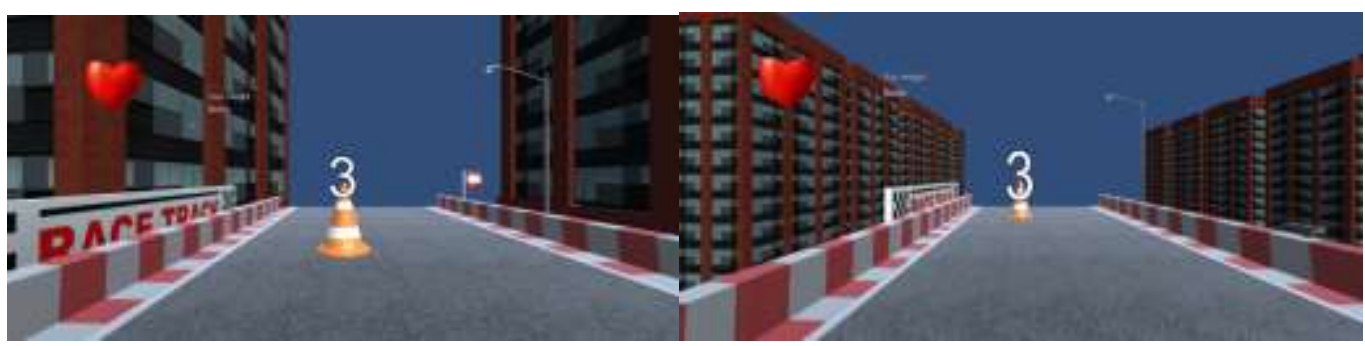

Figure 8. Comparison of Building Size and Street Lamp Size

Figure 8(the left side) is an environment created using the realistic proportions of an 11-story building (around 48m), while the right side of Figure 8 (right) is an environment that does not match realistic proportions.

\subsection{Brightness of Light}

The definition of objects and appearance of shadows depend on the brightness of light. Therefore, this simulation was created to see how different degrees of brightness and resulting shadows in the real word would appear in virtual reality. In Figure 9, "direction light" in Unity3D was used to enable light adjustments into 3 stages: sunlight (outside), middle (cloudy day), and night, each at a brightness that is similar to that of light in the real world.

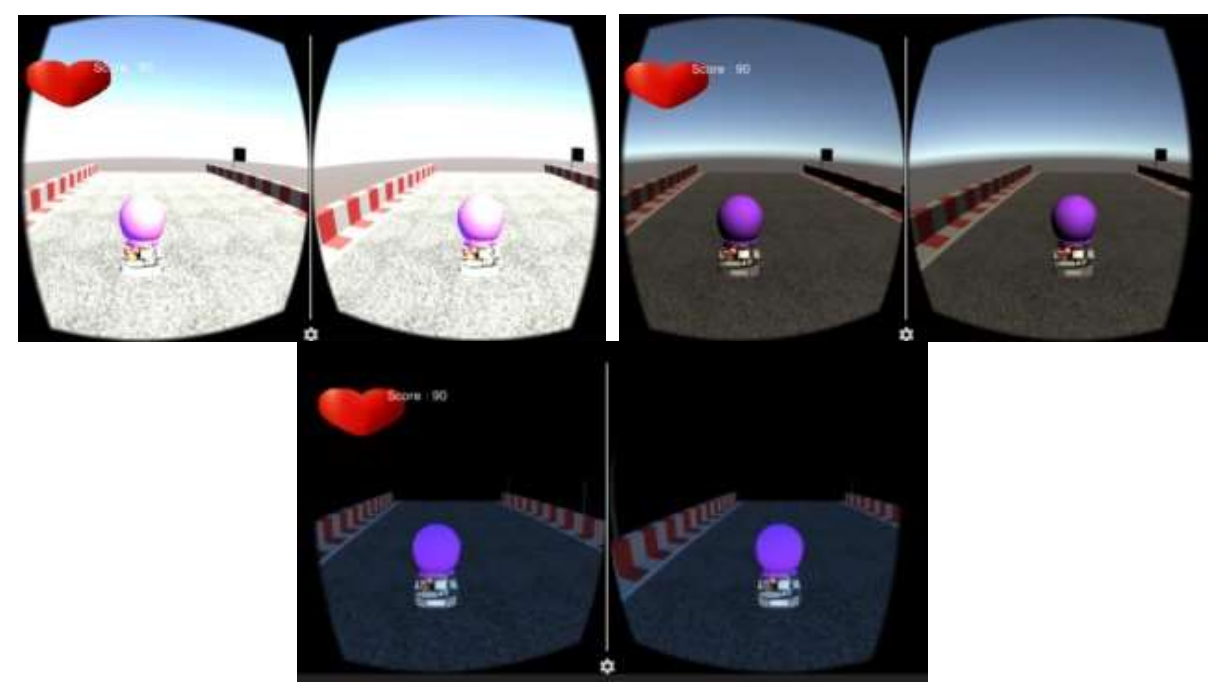

Figure 9. Is a Test on the Brightness of Light: Strong (Sunlight), Middle (Cloudy Day), Weak (Street Lamps, Night Time) 
Figure 10 was created to test the degree of dizziness that occurs through the definition and shadow of objects under the middle light value in Figure 9. Nearby objects have definition and shadows. Therefore, the brightness and movements of realistic shadows must be adjusted according to the direction of light. A character was placed in a location that is not influenced by any other light, and weak conditions of shadows and color definition were applied. In Unity3D, shading adjustments according to brightness are divided into a range in which shadows are generated and a range in which shadows are not generated. Therefore, we can see how the location of the user's eyes and the character's distance becomes closer. Figure 10 shows how the focal distance becomes closer.

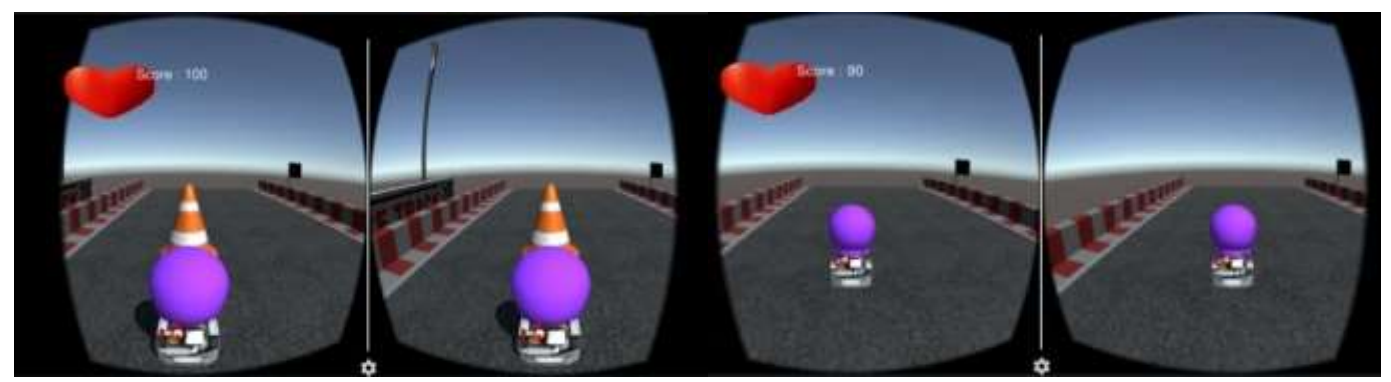

Figure 10. (Left: Near with Shading, Right: Far without Shading)

\subsection{Changes in Movement Speed from Moving Distances}

Adjusting the character's movement speed was necessary in order to test whether dizziness occurs as a result of the character's movement. The speed adjustment function enabled movements from $0-100 \mathrm{~km} / \mathrm{hr}$. In the background were nearby road boundaries and far-away mountains and street lamps. This was intended to express the motion parallax phenomenon within the given space because the nearby road boundaries will blur as the character's speed increases while far-away mountains will appear unmoved. And when movement speed according to distance proportions is expressed differently from the real world, the brain experiences a mismatched experience information phenomenon. Figure 11 was created in order to test whether degree of dizziness is stronger under these conditions.

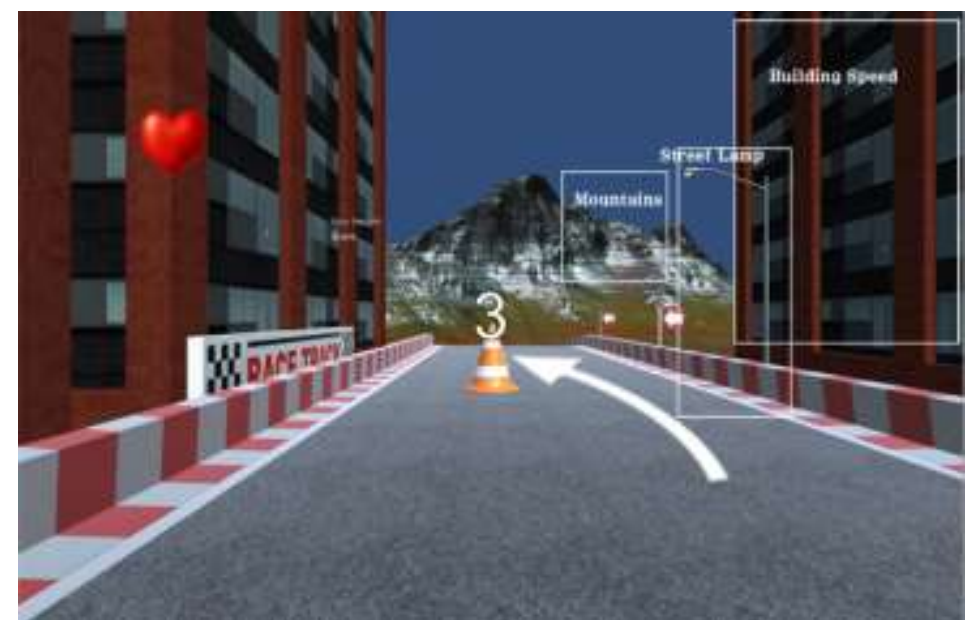

Figure 11. Speed Change and Motion According to Distance Movement

\section{Results of Sickness Simulation}


This section will organize the test results regarding the degree of dizziness that is induced by FoV-related user height simulation from 4.1, light and color brightness from 4.2, and changes in movement speed from moving distances from 4.3. First, we used the Google Cardboard device and the Gear VR Device with the Samsung Galaxy Note 7 for HMD devices. However, all 30 subjects experienced strong dizziness in all tests for Google Glasses after 5 or more seconds. Thus, these results were excluded from this paper's results. The differences between these results are shown in Table 5. Test subjects were 15 adult males and 15 adult females for a total of 30 adults. Subjects were made to express a degree of dizziness on a scale of 1 to 5 . There was a 5-minute testing interval from viewing one video to the next.

Table 5. Google Cardboard and Samsung Gear VR

\begin{tabular}{|l|l|l|}
\hline Sickness Factor & Google Cardboard & Samsung Gear VR \\
\hline HMD Frame Speed & Smartphone App Support & Smartphone App Support \\
\hline FoV & $90^{\circ}$ & $101^{\circ}$ \\
\hline $\begin{array}{l}\text { Distance between lens } \\
\text { and smartphone }\end{array}$ & $4 \mathrm{~cm}$ & $3 \mathrm{~cm}$ \\
\hline Lens Aperture & $2.5 \mathrm{~cm}$ & $4 \mathrm{~cm}$ \\
\hline
\end{tabular}

\subsection{Simulation Test on FoV-related User Height}

This test was conducted according to the proportional size of objects and the background at an optimized field-of-view (FoV) by having users (test subjects) selects their height. This test was regarding the degree of dizziness that is induced when the size and FoV of objects and the background does not match what the brain normally perceives in the real world. After testing the dizziness value of images that match and do not match the user's height, a test was conducted on mismatching experience information. The rectangular box in Figure 12 shows test results regarding the degree of dizziness symptoms that appear as a result of the experience information mismatch phenomenon. 14 people answered 3 for "Height + Experience Information Mismatch", 7 people answered 4 , and 2 people answered 5 .

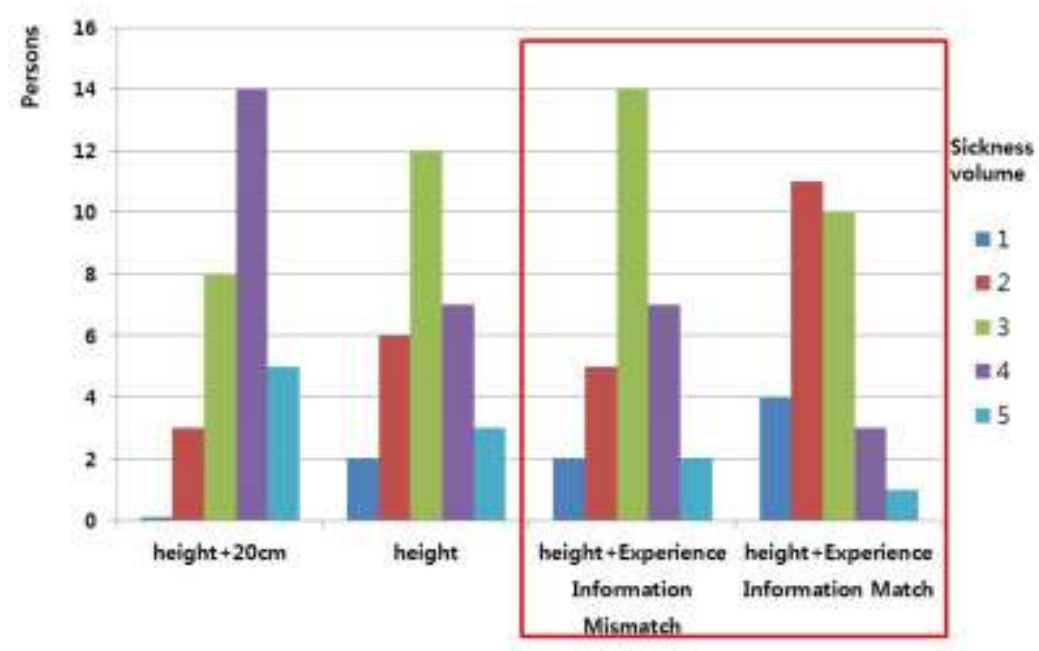

Figure 12. Analysis on the Degree of Dizziness Regarding Experience Information Mismatch from FoV Based on User Height 


\subsection{Color Brightness Test}

The results shown in Figure 13 are an analysis of the degree of dizziness according to environmental brightness. The brightness of light was divided into strong (sunlight), middle (light on a cloudy day), and weak (night light). There were many users who experienced level 3-5 dizziness in strong light and many who experienced level 1-3 dizziness in middle light, exhibiting the most stable distribution. Dizziness was measured at a normal level in weak light.

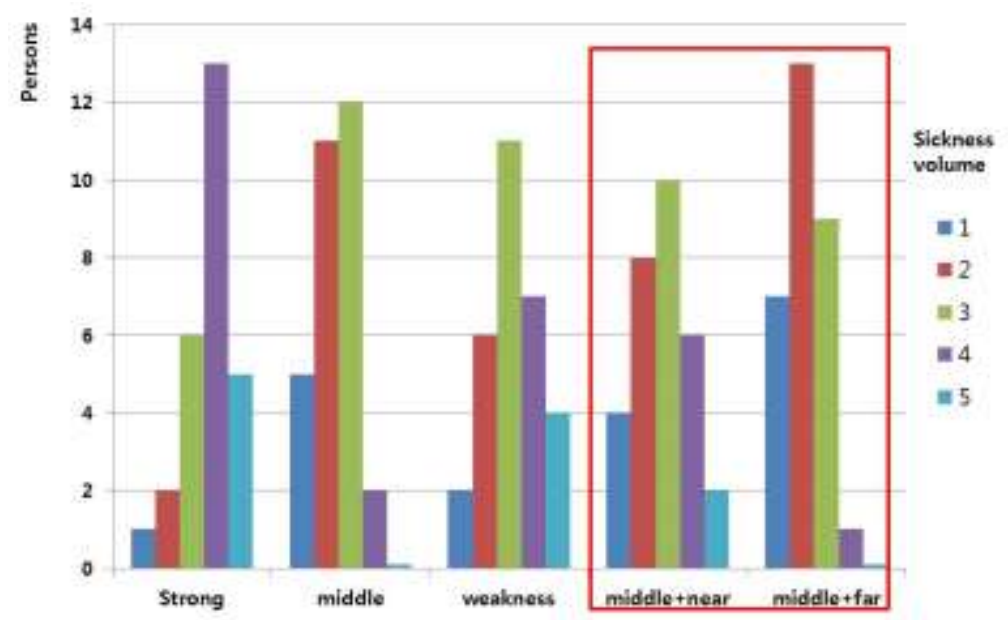

Figure 13. Analysis on the Degree of Dizziness Regarding Experience Information Mismatch Based on Color Brightness

The rectangular box in Figure 13 is regarding a test on mismatched experience information in the middle light environment, and shows results from a test conducted on the definition and shadow of objects that occurs as a result of light. 8 people reported level 2 and 10 people reported level 3 dizziness at middle + near, which was higher than the dizziness that was experienced at middle + far. Definition and shadows are phenomena that match experience information. Figure 10 shows how the user and character's distance can be described as the focal distance and dizziness may occur because the focal distance is too short. An additional test (not performed in this study) must be conducted on changes in a focal distance.

\subsection{Test on FoV-related User Height Test on Changes in Movement Speed According to Moving Distances}

During a test on speed, we compared a set speed against the acceleration from the character's starting speed. This was a test that enabled users to experience the real world phenomenon in which objects do not start off at a set speed when moving, but gradually accelerate to a faster speed, and gradually slowdown in order to stop. This test was meant to deliver experience information to users, but subjects actually experienced more dizziness with gradual acceleration as shown in the results in Figure 14. In the same way, the rectangular box is regarding a test on mismatched experience information. For constant background, passing objects, far-away mountains, and speed did not change according to distance proportions. For distance proportional speed, nearby passing objects and far-away mountains were properly set according to distance proportions. Results showed that less dizziness was experienced when experience information matched a set speed, but subjects experienced much dizziness when there were changes in speed, regardless of the experience information in tests regarding set speed and acceleration. 


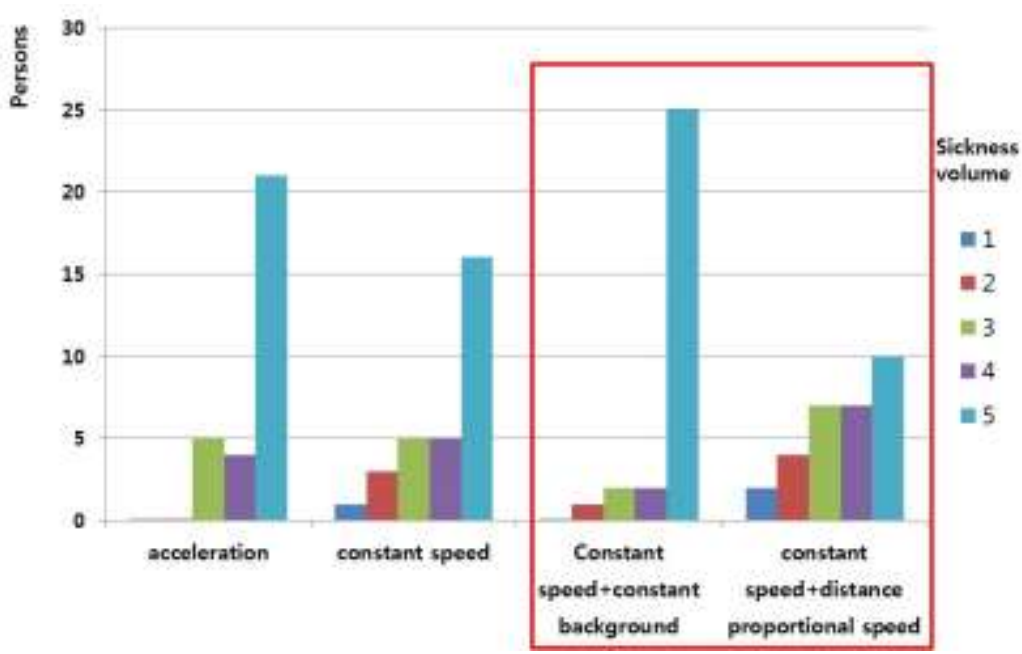

\section{Figure 14. Analysis of the Degree of Dizziness Regarding Changes in Speed Resulting from Moving Distances}

\section{Results}

This paper conducted a test that implemented and analyzed a simulation of the elements that should have been considered in the production stage in order to minimize simulation sickness from virtual reality. Through analyzing the elements that must be considered when implementing a virtual reality to be nearly identical to the real world, we have found results that were slightly different from existing knowledge. Although further testing would be required, this study was primarily a test on how much the phenomena triggered by mismatching experience information influence dizziness, through which we found that simulating information from the real world exactly as is in virtual reality does not necessarily minimize dizziness. This analysis data are expected to be required and necessary from the perspective of VR developers and users, and that it will be used by developers and gamers in future VR content or the VR game development stage.

\section{Acknowledgments}

This paper is a revised and expanded version of a paper entitled "Study on Virtual Reality Simulation Sickness Factors", presented at MITA 2016, Souphanouvong University(SU), Luang Prabang, Lao PDR and July 4 - 6, 2016.

\section{References}

[1] https://news.samsung.com/kr/hfj1F

[2] H. McLellan, Editor, "Situated learning perspectives", Englewood Cliffs, Educational Technology Publications, New Jersey, USA (1996).

[3] A.K. Jin and Y.M. Lim, "A study on reality representation of digital media art by digital technology", Journal of Digital Design, vol.10, no.3, (2010), pp.93-102.

[4] E. M. Kolasinski, "Simulator sickness in virtual environments (ARI 1027)", Army Research Institute for the Behavioral and Social Sciences, USA, (1995).

[5] E. Groen and J. Bos, "Simulator sickness depends on frequency of the simulator motion mismatch: An observation", Teleoperators and Virtual Environments, vol. 17 issue 6, (2008), pp.584-593.

[6] https://docs.unrealengine.com/latest/KOR/Platforms/VR/ContentSetup/index.html

[7] J. J. Lin, H. B. L. Duh, D. E. Parker, H. Abi-Rached and T. A. Furness, "Effects of field of view on presence, enjoyment, memory and simulator sickness in a virtual environment". Proceedings of IEEE(VRST'06), IEEE Computer Society, Orlando, USA, (2002), pp.164-171.

[8] https://developer3.oculus.com/documentation/intro-vr/latest/concepts/bp_app_simulator_sickness/

[9] http://www.google.com/cardboard 
[10] Yangmi lim, "Analysis of 3D Space Direction Expression for Making Gradually Induced Direction of Stereoscopic 3D," Journal of Digital Design, vol.13, no.4, (2013), pp.643-652.

[11] B.D. Lawson, D.A. Graeber and A.M. Mead, "Signs and symptoms of human syndromes associated with synthetic experience" In K.M. Stanney (Eds.) Handbook of virtual environments: Design, implementation, and applications, Mahwah, NJ, (2002).

[12] http://www.samsung.com/global/galaxy/gear-vr/

[13] http://www.virtualrealitytimes.com/2015/05/24/chart-fov-field-of-view-vr-headsets/

\section{Authors}

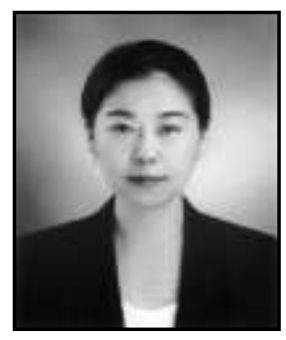

YangMi Lim, She has worked as an assistant professor at Duksung Women's University, Seoul, South Korea, since 2010. She received her BS Degrees in Media Engineering from Seoul National University of Technology, Seoul, Korea, in 1989 and 1993, and MS degrees in Audio and Visual Communication from Kyushu Institute of Design National University, Fukuoka, Japan. She received a Ph.D. in Art and Technology at Chung-Ang University. Her research interests are image processing, computer graphics and interactive media art.

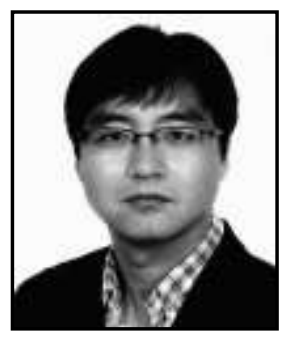

SangHun Nam, He received his B.S Degree in Mechanical Design from Chung-Ang University. He received M.S and Ph.D. in Image Science from Graduate School of Advanced Imaging Science, Multimedia \& Film in Chung-Ang University. His major is Computer Graphics \& Virtual Environments. He completed a post-doctoral course at Virtual Environment Lab in Chung-Ang University from 2012 to 2013. His research area includes virtual environments, spatial sketch and interaction, interactive media art. 
International Journal of Control and Automation

Vol. 10, No. 5 (2017) 